\title{
Oligosaccharide composition of the neurotoxin-responsive sodium channel of mouse neuroblastoma and requirement of sialic acid for biological activity *
}

\author{
Manabu Negishi ${ }^{a, 1}$, J. Albert van Kuik ${ }^{b}$, Johannes F.G. Vliegenthart ${ }^{b}$ \\ and Mary Catherine Glick ${ }^{\text {a }}$ \\ a Department of Pediatrics, School of Medicine, University of Pennsylvania and The Children's Hospital of \\ Philadelphia, Philadelphia, Pennsylvania 19104 (USA) \\ ${ }^{b}$ Bijvoet Center for Biomolecular Research, Department of Bio-Organic Chemistry, Utrecht University, \\ Utrecht (Netherlands)
}

\begin{abstract}
A glycoprotein, $M_{\mathrm{r}} 200000$, which has the biological activity of the neurotoxin-responsive $\mathrm{Na}^{+}$ channel, was isolated from a clonal line of mouse neuroblastoma cells, N-18. The glycoprotein was purified to homogeneity in $18 \%$ yield by methods used to purify glycoproteins, which included metabolic labeling of the cells with $\mathrm{L}-\left[{ }^{3} \mathrm{H}\right]$ fucose and binding of the radioactive glycoproteins to WGAand lentil-Sepharose, and DEAE-cellulose. The glycoprotein has biological activity of neurotoxin-responsive ion flux when reconstituted into artificial phospholipid vesicles. This activity was shown to depend on the presence of sialic acid since treatment of the purified, reconstituted glycoprotein with Vibrio cholerae neuraminidase abolished the response to neurotoxins of ${ }^{86} \mathrm{Rb}$ flux. The $\left[{ }^{3} \mathrm{H}\right] \mathrm{fucose}$-containing glycopeptides derived by Pronase digestion of the glycoprotein were characterized by affinity to immobilized lectins and contained di-, tri-, and tetra-antennary oligosaccharides in a ratio of $2: 4: 3$. Most of the glycopeptides were sialylated as shown by binding characteristics to immobilized serotoninSepharose with and without neuraminidase. The structure of the diantennary oligosaccharides was elucidated by $500-\mathrm{MHz}^{1} \mathrm{H}$ NMR spectroscopy. The Con A-bound fraction contains $\alpha$-NeuNAc- $(2 \rightarrow$ 6)-bound group on the GlcNAc ${ }^{5}$ antenna and an $\alpha$-NeuNAc-(2 $\left.\rightarrow 3\right)$-bound groups on the GlcNAc ${ }^{5}$ antenna. An $\alpha$-L-fucosyl group is $(1 \rightarrow 6)$-bound to the Asn core $\mathrm{GlcNAc}^{t}$ residue.
\end{abstract}

\section{INTRODUCTION}

The glycoprotein nature of the neurotoxin-responsive sodium channel in mouse neuroblastoma cells was shown by demonstration of channel activity after reconstitution of a partially purified glycoprotein into artificial phospholipid vesicles ${ }^{1,2}$. In

Correspondence to: Dr. M.C. Glick, The Children's Hospital of Philadelphia, 34th \& Civic Center Boulcvard, Philadelphia, PA 19104, USA.

* Dedicated to Proffesor Jean Montreuil.

1 Current address: Department of Physiological Chemistry, Kyoto University, Sakyo-ku, Kyoto 606, Japan. 
addition, recovery in the active fraction of the metabolic label, L- $\left[{ }^{3} \mathrm{H}\right]$ fucose, a precursor of glycoproteins which does not follow another metabolic route, supports the glycoprotein composition of the active sodium channel. Initial studies revealed that the presence of $\mathrm{mM} \mathrm{D}$-galactose or L-fucose in the growth medium inhibited $\mathrm{Na}^{+}$channel activity of neuroblastoma cells in culture ${ }^{3}$. Subsequently, inhibitors of glycoprotein synthesis, tunicamycin ${ }^{4}$ or swainsonine ${ }^{2}$, were shown to cause decreased saxitoxin binding and a reduction in channel activity, respectively. These results suggested that the ion flux which is responsive to neurotoxins may depend on the glycosylation of the protein.

The active $\mathrm{Na}^{+}$channel can be studied by several methods, i.e., the detection of neurotoxin-binding components ${ }^{5}$, measurement of ion flux by electrophysiological techniques ${ }^{6,7}$, utilization of oocyte-expression systems ${ }^{8}$, or radioactive-ion flux in response to neurotoxins ${ }^{9}$. We have used the latter method of radioactive-ion flux since it is amenable to following purification of a channel containing all the components necessary for the biological activity, thus precluding the isolation of only the neurotoxin-binding components. An advantage of these current studies was the use of a clonal cell line of mouse neuroblastoma ${ }^{10}$ which could be labeled metabolically, thus providing a marker to follow the isolation of the glycoprotein. We had shown previously ${ }^{11}$ that ion flux in the mouse neuroblastoma cells coincides with the presence of a glycoprotein, $M_{\mathrm{r}} 200000$; therefore, the purification resided in the ability to detect this glycoprotein which contained a radioactively-labeled carbohydrate precursor and maintained biological activity.

In spite of the studies describing the molecular details of the $\mathrm{Na}^{+}$channel ${ }^{12}$, the oligosaccharide components have not been described in detail. We report herein a mild method for the purification of a large glycoprotein which has the biological activity accorded to the neurotoxin-responsive $\mathrm{Na}^{+}$channel, the partial oligosaccharide composition, and the basis for the involvement of carbohydrate in the discrimination of ion flux.

\section{EXPERIMENTAL}

Materials.—Cell culture medium was from GIBCO and Hazelton Laboratories. WGA-, Con A-, and lentil lectin-Sepharose 4-B were from Pharmacia. L-PHAagarose was from E.Y. Laboratories. Nonidet P-40 was from Bethesda Research Laboratories and DEAE-cellulose and Bio-Beads SM-2 were from BioRad. ${ }^{86} \mathrm{Rb}$ $(6 \mathrm{mCi} / \mathrm{mg}), \mathrm{L}-\left[5,6-{ }^{3} \mathrm{H}\right]$ fucose $(56 \mathrm{Ci} / \mathrm{mmol})$, and $\mathrm{D}-\left[6-{ }^{3} \mathrm{H}\right] \mathrm{glucosamine}(31.3$ $\mathrm{Ci} / \mathrm{mmol}$ ) were from NEN; Pronase, Vibrio cholerae neuraminidase, and tetrodotoxin were from Calbiochem-Behring. Veratridine and Leiurus quinquestriatus scorpion venom were from Sigma. Serotonin-Sepharose of high affinity was prepared by Dr. C.P. Stowell. $\mathrm{D}_{2} \mathrm{O}$ was obtained from Aldrich and 2-oleoyl-1palmitoylphosphatidylcholine from Avanti Biochemicals.

Cell culture and harvest. - For purification of the neurotoxin-responsive $\mathrm{Na}^{+}$ channel glycoprotein, a clonal cell line of mouse neuroblastoma, $\mathrm{N}-18^{10}$, was grown 
on $75-\mathrm{cm}^{2}$ Falcon flasks seeded at $2 \cdot 10^{6}$ cells per flask in Dulbecco's modified Eagle's medium containing $10 \%$ fetal calf serum at $37^{\circ}$ in an atmosphere of $5 \%$ $\mathrm{CO}_{2}$. After 3 days, fresh medium containing $\mathrm{L}-\left[{ }^{3} \mathrm{H}\right]$ fucose $(5 \mu \mathrm{Ci}$ per flask $)$ was added to radioactively label the glycoprotein and $0.5 \%$ dimethyl sulfoxide to enhance differentiation, and the cells were grown for $48 \mathrm{~h}^{11}$. Where noted $D-\left[{ }^{3} \mathrm{H}\right]$ glucosamine ( $5 \mu \mathrm{Ci} /$ flask) was used as the metabolic label.

The cells were harvested at $25^{\circ}$ as described ${ }^{11}$. Aliquots were removed for protein $^{13}$ and radioactivity determinations ${ }^{11}$, and cell counts. The cells were utilized between passage 30 and 45 of the original clone ${ }^{10}$ and were free of mycoplasma. Under these conditions of growth utilizing $\mathrm{L}-\left[{ }^{3} \mathrm{H}\right]$ fucose, the cells incorporated $3.25 \pm 0.10 \cdot 10^{5}$ (mean $\pm \mathrm{SE}$ ) $\mathrm{cpm} / \mathrm{mg}$ of protein, and contained $4.22 \pm 0.21$ (mean $\pm \mathrm{SE}$ ) $\mathrm{mg}$ of protein $/ 10^{8}$ cells, $n=20$ cell harvests.

Efflux of ${ }^{86} \mathrm{Rb}$. - In addition to the parameters which defined cell growth, the neurotoxin-responsive efflux of ${ }^{86} \mathrm{Rb}$ was examined at the time of each harvest. The assay was as described ${ }^{9,11}$ but on $25-\mathrm{mm}$ Corning dishes using $100 \mu \mathrm{M}$ veratridine and $5 \mu \mathrm{g}$ of scorpion venom $/ \mathrm{mL}$ of assay medium ${ }^{11}$ to stimulate ${ }^{86} \mathrm{Rb}$ efflux and $\mu \mathrm{M}$ tetrodotoxin to inhibit the stimulated efflux. The active efflux rate constant $^{9,11}$ obtained from the assay of the cells at 20 different times of harvest was $6.89 \pm 0.27 \cdot 10^{-2} \min ^{-1}$ (mean $\pm \mathrm{SE}$ ). At the same time, the passive efflux rate constant was only $1.09 \pm 0.06 \cdot 10^{-2} \mathrm{~min}^{-1}$ (mean $\pm \mathrm{SE}$ ). In no case were cells used for further studies when the response to neurotoxin stimulation was low (active efflux rate constant $<3.5 \cdot 10^{-2} \mathrm{~min}^{-1}$ ).

Purification of the glycoprotein. - After harvest, the washed cell pellet $\left(3 \cdot 10^{8}\right.$ cells) was extracted by shaking gently on ice for $5 \mathrm{~min}$ with $8 \mathrm{~mL}$ of $1 \% \mathrm{NP}-40$ in $0.02 \mathrm{M}$ Tris $\cdot \mathrm{HCl}, \mathrm{pH} 7.5$, in $0.15 \mathrm{M} \mathrm{NaCl}$ containing $\mathrm{mM} \alpha$-toluenesufonyl fluoride. The suspension was centrifuged for $5 \mathrm{~min}$ at $280 \mathrm{~g}$ and the supernatant solution was centrifuged further for $30 \mathrm{~min}$ at $27000 \mathrm{~g}^{1}$.

WGA-Sepharose $(5 \mathrm{~mL})$ was equilibrated with $0.02 \mathrm{M}$ Tris $\cdot \mathrm{HCl}, \mathrm{pH} 7.5$, containing $0.1 \% \mathrm{NP}-40$ and $\mathrm{mM} \alpha$-toluenesulfonyl fluoride (Buffer $A$ ), and then incubated with the detergent extract from $\mathrm{N}-18$ cells for $1 \mathrm{~h}$ at $4^{\circ}$ with gentle shaking ${ }^{1}$. The mixture was collected into a column $(1.2 \times 5 \mathrm{~cm})$ and washed with 25 $\mathrm{mL}$ of Buffer $A$. The bound glycoproteins were eluted successively with $0.02 \mathrm{M}$ and $0.1 \mathrm{M}$ GlcNAc in Buffer $A(20 \mathrm{~mL}$ each).

The fraction that was eluted from the WGA-Sepharose column with $0.02 \mathrm{M}$ GlcNAc was separated further on a column of DEAE-cellulose $(1 \times 16 \mathrm{~cm})$ pre-equilibrated with Buffer $A$. After washing with $0.1 \mathrm{M} \mathrm{NaCl}$ in Buffer $A$ (10 $\mathrm{mL}$ ), the radioactively-labeled glycoproteins were eluted in $1.5-\mathrm{mL}$ fractions with a linear salt gradient, $0.1-0.4 \mathrm{M} \mathrm{NaCl}$ in Buffer $A$. The radioactivity which was eluted with $0.25 \mathrm{M} \mathrm{NaCl}$ from DEAE-cellulose was collected and further separated in a column $(1 \times 6 \mathrm{~cm})$ containing lentil lectin-Sepharose $(5 \mathrm{~mL})$. The bound glycoproteins were eluted successively with $20 \mathrm{~mL}$ each of $0.04 \mathrm{M}$ and $0.2 \mathrm{M}$ methyl $\alpha$-D-mannopyranoside in $0.01 \mathrm{M}$ Tris $\cdot \mathrm{HCl}, \mathrm{pH} 8.0$, containing $0.1 \%$ NP-40, $0.15 \mathrm{M} \mathrm{NaCl}, \mathrm{mM} \mathrm{MgCl}, \mathrm{MM} \mathrm{CaCl}_{2}$, and $\mathrm{mM} \alpha$-toluenesulfonyl fluoride. 
$P A G E$. - In order to detect the glycoprotein at each stage of purification, aliquots were examined by poly(acrylamide)-gel electrophoresis (PAGE) under denaturing conditions ${ }^{11}$. The fractions from each preparation were combined according to radioactivity and dialyzed for $24 \mathrm{~h}$ against water at $4^{\circ}$. NP-40 was removed with Bio-Beads SM-2 and the fractions were lyophilized.

Gradient slab-gels of 7-14\% poly(acrylamide) were used with a 5\% stacking gel. The gels were fixed and stained for protein with Coomassie Brilliant Blue. To detect the radioactively-labeled glycoproteins, the stained gels were dried, cut into $1.5-\mathrm{mm}$ slices, solubilized with Protosol, and the radioactivity was counted in a liquid-scintillation counter. Proteins used as standards were: fibronectin, $M_{\mathrm{r}}$ 230000 (BRL); chicken breast muscle myosin, $M_{\mathrm{r}} 200000$ (Dr. Frank Pepe, Department of Anatomy, University of Pennsylvania); bovine serum albumin, $M_{\mathrm{r}}$ 68000 (Miles); ovalbumin, $M_{\mathrm{r}} 43000$ (ICN); and chymotrypsin, $M_{\mathrm{r}} 23000$ (Pharmacia), or prestained proteins (BRL) were used.

Reconstitution of the $\left[{ }^{3} \mathrm{H}\right]$ glycoprotein into phospholipid vesicles. - The $\left[{ }^{3} \mathrm{H}\right] \mathrm{glyco}-$ protcin was reconstitutcd into 2-olcoyl-1-palmitoylphosphatidylcholine in a protein-to-phospholipid ratio of $1: 10$ as described ${ }^{1}$. After removing the excess detergent on a column $(0.5 \times 5 \mathrm{~cm})$ of Bio-Beads SM-2, the radioactive vesicles were centrifuged at $76000 \mathrm{~g}$ for $2 \mathrm{~h}$. The pellet was resuspended in $20 \mathrm{mM}$ potassium phosphate buffer, $\mathrm{pH} 7.4$, with $100 \mathrm{mM} \mathrm{NaCl}(0.3 \mathrm{~mL})$ and an aliquot was removed for radioactivity counting to determine the percentage of radioactively-labeled glycoprotein reconstituted. The remaining suspension was divided into three aliquots. To two aliquots were added $250 \mu \mathrm{M}$ veratridine and scorpion venom (12.5 $\mu \mathrm{g}$ per $\mathrm{mL}$ of vesicle suspension), and one of these contained a prior addition of $5 \mu \mathrm{M}$ tetrodotoxin. The third aliquot served as a control without neurotoxins. ${ }^{86} \mathrm{~Kb}(24 \mu \mathrm{Ci})$ was added to each fraction and, after $30 \mathrm{~min}$ at $25^{\circ}$, the vesicle preparations were each passed through columns $(0.5 \times 5 \mathrm{~cm})$ of Dowex $50 \mathrm{~W} \mathrm{X}-2$ cation-exchange resin to remove ${ }^{86} \mathrm{Rb}$ not taken up by the vesicles ${ }^{14}$. The vesicles were collected and counted in the liquid-scintillation counter. The percentage of ${ }^{86} \mathrm{Rb}$ flux which was stimulated by neurotoxins was that amount of radioactivity in the stimulated vesicles over that of the nonstimulated vesicles. Vesicles treated with tetrodotoxin and then stimulated served as a control for specific stimulation.

In some cases, the vesicles containing the reconstituted glycoprotein were treated with $V$. cholerae neuraminidase $\left(0.01\right.$ int. unit) for $5 \mathrm{~h}$ at $37^{\circ}$ in $0.1 \mathrm{~mL}$ of $20 \mathrm{mM}$ potassium phosphate buffer, $\mathrm{pH} 7.5$, containing $0.1 \mathrm{M} \mathrm{NaCl}$. Vesicles which served as a control were treated similarly but without neuraminidase. ${ }^{86} \mathrm{Rb}$ flux of the neuraminidase treated and nontreated vesicles was as described above.

Characterization of the glycopeptides derived from the $\mathrm{Na}^{+}$channel glycoprotein. - The fractions which were eluted from lentil lectin-Sepharose with $0.2 \mathrm{M}$ methyl $\alpha$-D-mannopyranoside were combined and passed over a column $(1 \times 10 \mathrm{~cm})$ of DEAE-cellulose to remove methyl $\alpha$-D-mannopyranoside and eluted with $0.5 \mathrm{M}$ $\mathrm{NaCl}$ in Buffer $A$. The collected $\left[{ }^{3} \mathbf{H}\right.$ ]glycoprotein was passed over a column $(0.5 \times 5 \mathrm{~cm})$ of Bio-Beads SM-2 to remove NP-40 and subsequently digested 
exhaustively with Pronase as described ${ }^{15}$. After passing through a column $(1 \times 40$ $\mathrm{cm}$ ) of Bio-Gel P-2 and lyophilization, the fraction was characterized by affinity to columns of Con A- and lentil lectin-Sepharose, and L-PHA-agarose as described $^{16-18}$.

For the analysis of serotonin-Sepharose binding of the glycopeptides ${ }^{18-20}$, the fractions to be examined were treated with or without neuraminidase $(0.01$ int. unit) for $24 \mathrm{~h}$ at $37^{\circ}$ in $0.1 \mathrm{~mL}$ of buffer. After treatment, each fraction was passed through a column $(0.5 \times 3 \mathrm{~cm})$ of serotonin-Sepharose and was eluted as described $^{2,18}$.

The size of the glycopeptides was determined with a column $(1 \times 120 \mathrm{~cm})$ of Bio-Gel P-10 in $50 \mathrm{mM}$ ammonium acetate buffer ${ }^{2}$. The charge characteristics were examined with a DEAE-cellulose column $(1 \times 10 \mathrm{~cm})$, glycopeptides being eluted with a gradient of $0.5-30 \mathrm{mM}$ potassium phosphate buffer, $\mathrm{pH} 6.8$, followed by $100 \mathrm{mM}$ potassium phosphate buffer as described ${ }^{15}$.

${ }^{1} H$ NMR spectroscopy. - For ${ }^{1} \mathrm{H}$ NMR analysis, the carbohydrate sample was repeatedly treated with $\mathrm{D}_{2} \mathrm{O}$ at room temperature, with intermediate lyophilization, finally with $99.96 \% \mathrm{D}_{2} \mathrm{O} .500-\mathrm{MHz}{ }^{1} \mathrm{H}$ NMR spectra were obtained on a Bruker WM-500 spectrometer (SON hf-NMR facility, Department of Biophysical Chemistry, University of Nijmegen) operating in the FT mode at a probe temperature of $27^{\circ 21}$. Resolution-enhancement of the spectrum was achieved by Lorenzianto-Gaussian transformation ${ }^{22}$. Chemical shifts $(\delta)$ are expressed downfield from the signal for internal sodium 4,4-dimethyl-4-silapentane-1-sulfonate, and measured by references to internal acetone ( $\delta$ 2.225).

\section{RESULTS}

Purification of the glycoprotein, $\mathrm{M}_{r}$ 200000. - We had shown previously ${ }^{1,11}$ that the activity of the $\mathrm{Na}^{+}$channel in mouse neuroblastoma coincided with a glycoprotein, $M_{\mathrm{r}} 200000$. Therefore, all of the purification methods resided in the ability to detect this glycoprotein on poly(acrylamide) gels using a radioactively-labeled glycoprotein precursor (Table I).

Mouse neuroblastoma cells, $\mathrm{N}-18$, metabolically labeled with $\mathrm{L}_{\mathrm{L}}\left[{ }^{3} \mathrm{H}\right] \mathrm{fucose}$, were extracted with $1 \% \mathrm{NP}-40$ at $5^{\circ}$. The extract was fractionated on WGA-Sepharose (Fig. 1A). The fractions which were eluted with $20 \mathrm{mM}$ GlcNAc contained $58 \%$ of the glycoprotein, $M_{\mathrm{r}} 200000$, that was originally found in the NP-40 extract. Lesser amounts were recovered in the fractions which were eluted with $0.1 \mathrm{M}$ GlcNAc or which were unbound, 1.5 and $11 \%$, respectively. The yield of glycoprotein was calculated from the radioactivity recovered after separation of an aliquot of the column fractions by PAGE.

Fig. 2A shows the profile after PAGE of fucose-containing glycoproteins in the fractions which were eluted from WGA-Sepharose with $20 \mathrm{mM}$ GlcNAc. Although more than $50 \%$ of the glycoprotein, $M_{\mathrm{r}} 200000$, was recovered in the fraction (Table I), only $\sim 10 \%$ of the total radioactivity in the fraction could be attributed 


\section{TABLE I}

Purification and biological activity of glycoprotein, $M_{\mathrm{r}} 200000$

\begin{tabular}{|c|c|c|c|c|}
\hline \multirow{2}{*}{$\begin{array}{l}\text { Fraction of } \\
\text { N-18 cells }\end{array}$} & \multicolumn{2}{|c|}{ Radioactivity recovered $b$} & \multirow{2}{*}{$\begin{array}{l}\text { Yield of } \\
\text { glycoprotein, } \\
M_{\mathrm{r}} 200000(\%)^{c}\end{array}$} & \multirow{2}{*}{$\begin{array}{l}\text { Biological activity } \\
\text { (activation by } \\
\text { neurotoxins, } \%)^{e}\end{array}$} \\
\hline & $\times 10^{3} \mathrm{cpm}$ & Per cent of total & & \\
\hline NP-40 extract & $5190 \pm 362$ & 100 & 100 & \\
\hline \multicolumn{5}{|l|}{ WGA-Sepharose } \\
\hline $0.02 \mathrm{M} \mathrm{GlcNAc}$ & $845 \pm 64$ & $16.4 \pm 1.0$ & $58.5 \pm 4.1$ & 8 \\
\hline \multicolumn{5}{|l|}{ DEAE-cellulose } \\
\hline $0.25 \mathrm{M} \mathrm{NaCl}$ & $154 \pm 15$ & $3.1 \pm 0.4$ & $27.2 \pm 1.3$ & 25 \\
\hline \multicolumn{5}{|l|}{ Lentil-Sepharose } \\
\hline $0.2 \mathrm{M} \alpha$-D-Man $p \mathrm{OMe}$ & $47 \pm \quad 5$ & $1.0 \pm 0.13$ & $18.4 \pm 2.0$ & 62 \\
\hline
\end{tabular}

a The cells $\left(1 \cdot 10^{8}\right)$ were labeled metabolically with $L-\left[{ }^{3} H\right]$ fucose. All details are described in the Experimental section. ${ }^{b}$ Mean and standard deviation, $n=10{ }^{c}$ Calculated from the radioactivity recovered from sliced poly(acrylamide) gels at $M_{\mathrm{r}}$ 200000. Mean and standard deviation, $n=3 .{ }^{d}$ Each fraction was reconstituted into artificial phospholipid vesicles and flux of ${ }^{86} \mathrm{Rb}$ was measured in response to neurotoxins as described in the Experimental section. ${ }^{e}$ Per cent increase of ${ }^{86} \mathrm{Rb}$ flux after stimulation with $250 \mu \mathrm{M}$ veratridine and $12.5 \mu \mathrm{g}$ of scorpion venom $/ \mathrm{mL}$ of vesicle suspension vs. nonstimulated vesicles. Nonstimulated flux of ${ }^{86} \mathrm{Rb}$ was $5000-6000 \mathrm{cpm}$. Inhibition of ${ }^{86} \mathrm{Rb}$ flux by 5 $\mu \mathrm{M}$ tetrodotoxin was $90 \%$ or greater.

to this glycoprotein. Further purification was achieved by chromatography on DEAE-cellulose (Fig. 1B). The glycoprotein, $M_{\mathrm{r}} 200000$, was found enriched in the fractions that were eluted after the $0.25 \mathrm{M} \mathrm{NaCl}$ fractions (Fractions 25-29, Fig. 1B). Only 3\% of the applied radioactivity was recovered in Fractions 25-29 (Fig. 1B) although the fractions contained $27 \%$ of the glycoprotein (Table I). When these DEAE fractions were visualized by PAGE, Coomassie Blue staining of the electropherogram showed other proteins present, but in lesser amounts than glycoprotein, $M_{\mathrm{r}} 200000$. One fourth of the radioactivity was recovered in the position of myosin (Fig. 2B), the reference protein for the glycoprotein. The majority of the radioactive glycoproteins were found in the fractions which were unbound to DEAE-cellulose (Fig. 2C).

The next procedure, affinity chromatography on lentil lectin-Sepharose, resulted in purification of the glycoprotein to apparent homogeneity. The DEAE-cellulose fractions, 25-30 (Fig. 1B), were combined and chromatographed over lentil lectin-Sepharose, and the fractions which were eluted with $0.2 \mathrm{M}$ methyl $\alpha$-D-mannopyranoside (Fig. 1C) were shown by PAGE to contain solely the glycoprotein, $M_{\mathrm{r}} 200000$ (Fig. 3A). The final yield of glycoprotein, $M_{\mathrm{r}} 200000$, was $18 \%$ of that found in the NP-40 extract (Table I). PAGE of the purified fraction showed only one band stained with Coomassie Brilliant Blue at the mobility of myosin (data not shown). Isoelectrofocusing of another preparation had a pI of 4.6 and no minor species.

Although the yield $(12 \%)$ of the glycoprotein recovered in the fraction which was eluted from lentil lectin-Sepharose with $40 \mathrm{mM}$ methyl $\alpha$-D-mannopyranoside was similar to that recovered (18\%) in the more tightly bound fraction, purification 


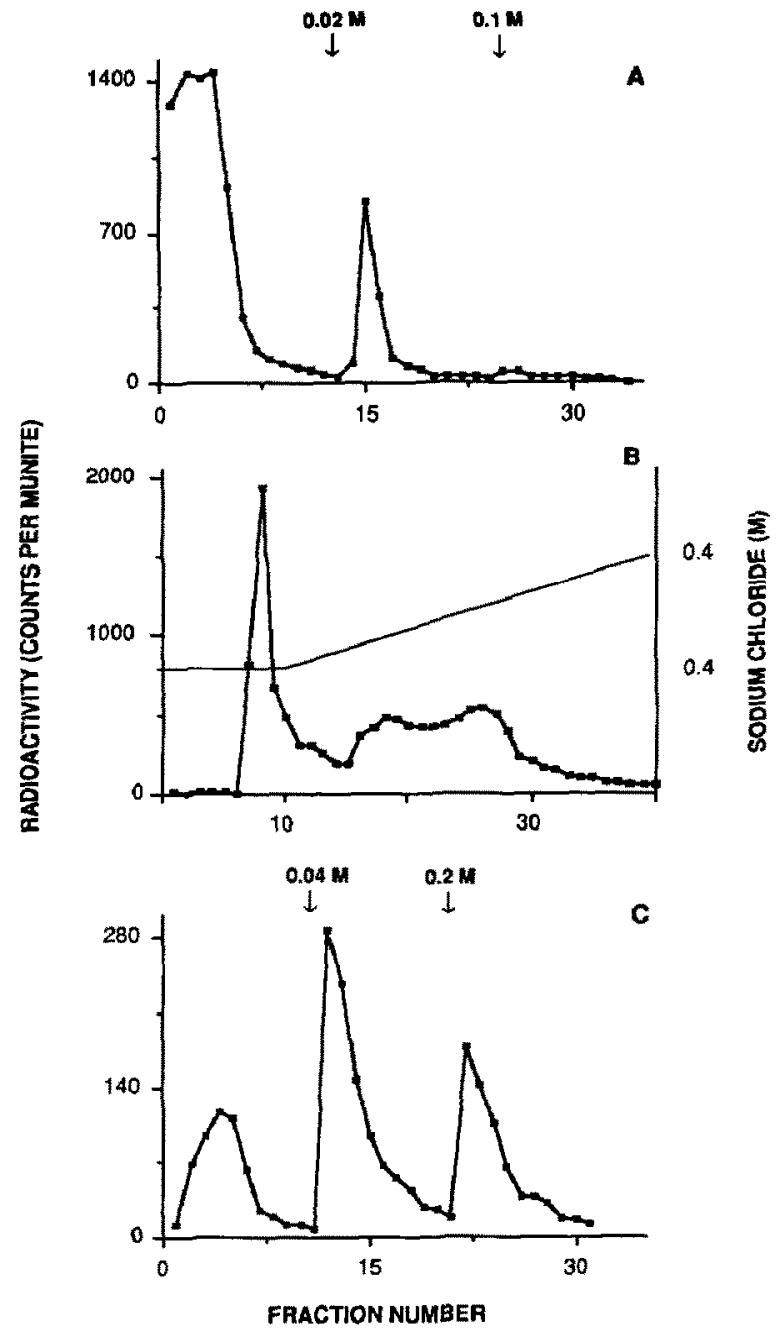

Fig. 1. Glycoprotein, $M_{\mathrm{r}} 200000$, was purified after extraction with $1 \%$ NP-40 from N-18 cells, metabolically labeled with $\left.\mathrm{L}-{ }^{3} \mathrm{H}\right] \mathrm{fucose}$. (A) The extract was applied to WGA-Sepharose and after washing was eluted with $0.02 \mathrm{M}$ and $0.1 \mathrm{M}$ GicNAc, indicated by arrows, respectively. An aliquot of each fraction was removed to determine the radioactivity. (B) The fractions which were eluted with 0.02 M GIcNAc were combined and further fractionated by chromatography on DEAE-cellulose using a gradient of $\mathrm{NaCl}$. (C) After the radioactivity was determined in aliquots of each fraction, Fractions 25-30 were combined and chromatographed on lentil lectin-Sepharose. The radioactively-labeled glycoproteins were eluted with $0.04 \mathrm{M}$ and $0.2 \mathrm{M} \alpha-\mathrm{D}-\mathrm{Man} p \mathrm{OMe}$, indicated by arrows, respectively. The profile was obtained by counting aliquots of each fraction. All details are described in the Fxperimental section.

was much less (compare Figs. $3 \mathrm{~A}$ and $\mathrm{B}$ ). Only $25 \%$ of the radioactivity in the fraction was found at the position of glycoprotein, $M_{\mathrm{r}}$ 200000. The unbound fraction contained most of the other proteins and glycoproteins (Fig. 3C). 

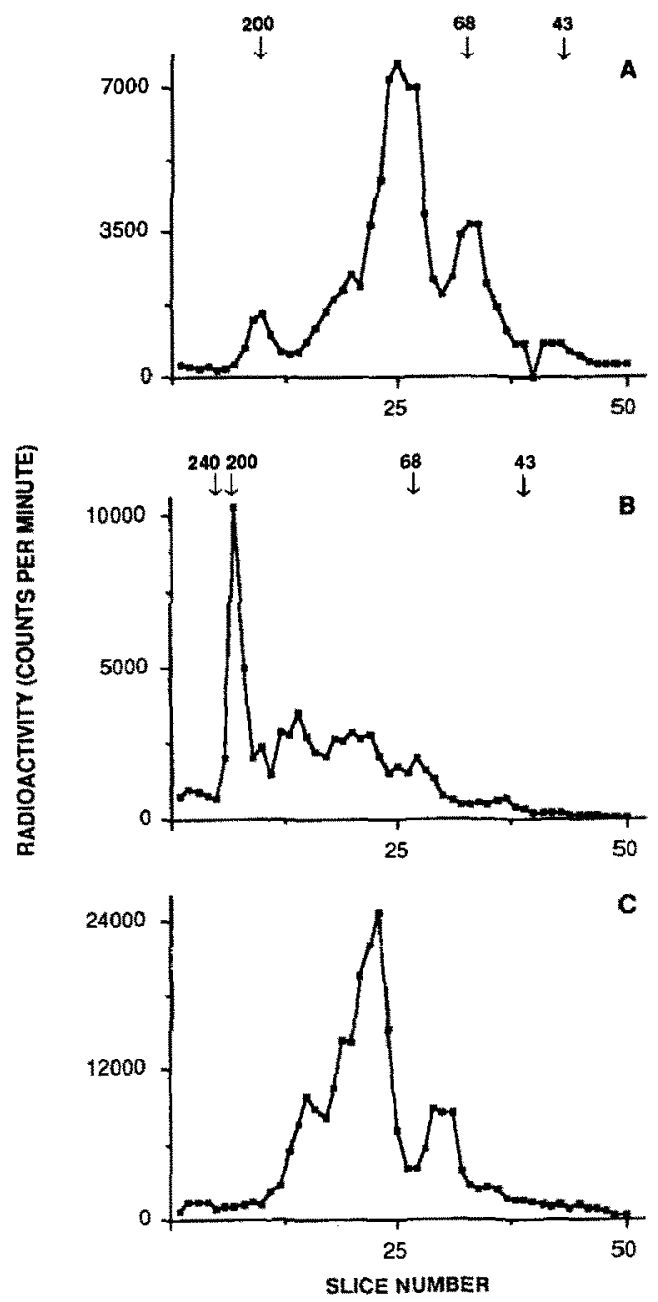

Fig. 2. Profiles after PAGE of $\left[{ }^{3} \mathrm{H}\right]$ fucose-labeled glycoproteins from $\mathrm{N}-18$ cells. The glycoproteins were eluted from WGA-Sepharose (see Fig. 1A) and subsequently purified by DEAE-cellulose (see Fig. 1B). Fractions which were (A) eluted from WGA-Sepharose with $0.02 \mathrm{M} \mathrm{GlcNAc}$, (B) eluted at $0.25 \mathrm{M} \mathrm{NaCl}$ from DEAE-cellulose, or (C) unbound to DEAE-cellulose were treated as described in the Experimental section, and subjected to PAGE (7-14\% gradient) under denaturing conditions. Numbers represent mol wt and positions of standard proteins $\left(\times 10^{-3}\right)$, as described in the Experimental section. Radioactivity in (B) and (C) is expressed as $10^{-1}$.

The purified glycoprotein was further characterized. In two experiments, 98 and $100 \%$, respectively, of the purified radioactively-labeled glycoprotein that was eluted from lentil lectin-Sepharose (Fig. 3A) bound to serotonin-Sepharose. Approximately $75 \%$ of the radioactively-labeled glycoprotein bound to Con A-Sepharose.

Biological activity of glycoprotein, $\mathrm{M}, 200000$.- It had been shown previously ${ }^{1}$ that partially purified glycoprotein, fractions, which were enriched for glycoprotein 


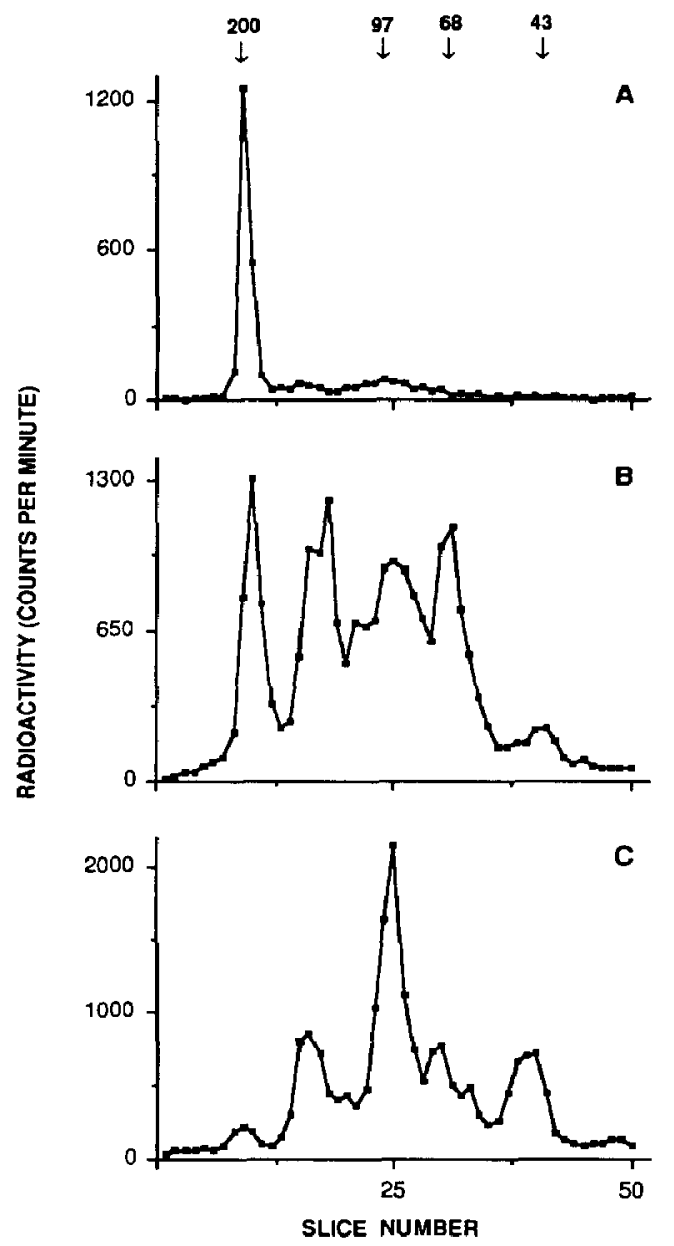

Fig. 3. Profiles after PAGE of $\left[{ }^{3} \mathrm{H}\right]$ fucosc-labeled glycoproteins fractionated on lentil lcctin-Scpharose (see Fig. 1C). (A) Glycoprotein which was eluted from lentil lectin-Sepharose with $0.2 \mathrm{M} \alpha$-DMan $p \mathrm{OMe}$; (B) glycoproteins which were eluted with $0.04 \mathrm{M} \alpha$-D-Man $p \mathrm{OMe}$; (C) unbound glycoproteins. See legend to Fig. 2 and the Experimental section for details.

$M_{\mathrm{r}} 200000$, had the activity of the neurotoxin-responsive $\mathrm{Na}^{+}$channel after reconstitution into artificial phospholipid vesicles. Therefore, it was critical to determine whether the glycoprotein now purified to apparent electrophoretic homogeneity retained the biological activity of the $\mathrm{Na}^{+}$channel.

When the glycoprotein (Fig. 3A) was reconstituted into artificial phospholipids and the vesicle preparation was stimulated with veratridine and scorpion venom, ${ }^{86} \mathrm{Rb}$ flux was increased (62\%) over the nonstimulated vesicles (Table I). Furthermore, the stimulated ${ }^{86} \mathrm{Rb}$ flux was inhibited $(90 \%)$ by tetrodotoxin, thus providing evidence that the glycoprotein had the biological activity accorded to excitable membranes. The biological activity was directly proportional to the purity of the 
TABLE II

The effect of neuraminidase on ${ }^{86} \mathrm{Rb}$ flux of vesicles containing glycoprotein, $M_{\mathrm{r}} 200000$

\begin{tabular}{|c|c|c|c|c|c|}
\hline \multirow[t]{2}{*}{$\begin{array}{l}\mathrm{Na}^{+} \text {channel } \\
\text { purification }^{a}\end{array}$} & \multicolumn{2}{|c|}{$\begin{array}{l}\text { Incorporated } \\
\text { into liposomes }\end{array}$} & \multirow{2}{*}{$\begin{array}{l}\text { Neuraminidase } \\
\text { added } \\
\text { (Int. units) }{ }^{b}\end{array}$} & \multirow{2}{*}{$\begin{array}{l}\text { Activation } \\
\text { by neurotoxins } \\
(\%)^{c}\end{array}$} & \multirow{2}{*}{$\begin{array}{l}\text { Inhibition } \\
\text { by TTX } \\
(\%)^{d}\end{array}$} \\
\hline & ${ }^{3} \mathrm{H}-\mathrm{cpm}^{a}$ & $\begin{array}{l}\text { Per cent } \\
\text { of fraction }\end{array}$ & & & \\
\hline Lentil-Sepharose & 535 & 50 & 0 & 62 & 90 \\
\hline \multirow{2}{*}{$0.2 \mathrm{M} \alpha$-D-Man $p \mathrm{OMe}$} & 767 & 50 & 0 & 67 & 100 \\
\hline & 767 & 50 & 0.01 & 4 & 76 \\
\hline
\end{tabular}

${ }^{a}$ Fraction from $\mathrm{N}-18$ cells metabolically labeled with $\mathrm{L}-\left[{ }^{3} \mathrm{H}\right]$ fucose. ${ }^{b}$ The $\left[{ }^{3} \mathrm{H}\right] \mathrm{glycoprotein}$ was reconstituted into phospholipid vesicles and incubated with $V$. cholerae neuraminidase. ${ }^{c}$ Per cent increase of ${ }^{86} \mathrm{Rb}$ flux after stimulation with $250 \mu \mathrm{M}$ veratridine and $12.5 \mu \mathrm{g}$ of scorpion venom $/ \mathrm{mL}$ of vesicle suspension vs. nonstimulated vesicles. Nonstimulated flux of ${ }^{86} \mathrm{Rb}$ was $5000-6000 \mathrm{cpm}$. ${ }^{d}$ Inhibition of ${ }^{86} \mathrm{Rb}$ flux in the presence of $5 \mu \mathrm{M}$ tetrodoxin (TTX). All details are described in the Experimental section.

glycoprotein, $M_{\mathrm{r}} 200000$, (Table I) and the amount of glycoprotein incorporated into the phospholipid vesicles.

Neuraminidase treatment of the reconstituted glycoprotein, $\mathbf{M}_{r}$ 200000. - The glycoprotein was reconstituted into artificial phospholipid vesicles. One half of the vesicle pellet was treated with $V$. cholerae neuraminidase. The other half was treated similarly without neuraminidase. Each vesicle preparation was then divided into three fractions to measure the neurotoxin stimulated and the nonstimulated flux of ${ }^{86} \mathrm{Rb}$, and inhibition by tetrodotoxin.

There was significantly reduced response $(<10 \%)$ of the neuraminidase-treated vesicles to activation by the neurotoxins, whereas the vesicles treated similarly but without neuraminidase showed a flux of ${ }^{86} \mathrm{Rb}$, which was $67 \%$ greater than that of the nonstimulated vesicles (Table II). In addition, the stimulated flux was inhibited by tetrodotoxin.

Characterization of glycopeptides derived from glycoprotein, $\mathbf{M}_{r}$ 200000. - In order to characterize the oligosaccharides of the glycoprotein (Fig. 3A), the binding properties of the glycopeptides to immobilized lectins used in series were examined. Scheme 1 shows the sequence of lectin chromatography and the percentage of radioactivity recovered at each step. The fucose-labeled glycopeptides which were unbound to immobilized Con A were passed over lentil lectinSepharose, and subsequently the unbound glycopeptides were passed over LPHA-agarose. Only $14 \%$ of the fucose-labeled glycopeptides remained unbound after this sequence of lectins.

Approximately 50\% (Scheme 1) of the fucose-labeled glycopeptides which were Con A unbound contained an $\alpha$-L-fucosyl group $(1 \rightarrow 6)$-linked to the core GlcNAc residue, and were therefore either of the triantennary type or were diantennary and contained an intersecting $\beta$-D-Glc $p$ NAc group $[\beta-\mathrm{D}-\mathrm{Glc} p \mathrm{NAc}-(1 \rightarrow 4)-\beta-\mathrm{D}-$ $\operatorname{Man} p-(1 \rightarrow 4)-\beta$-D-Glc $p$ NAc]. Glycopeptides having these characteristics will bind to immobilized lentil lectin after passage through a Con $A$ column ${ }^{17,18}$. Further, 


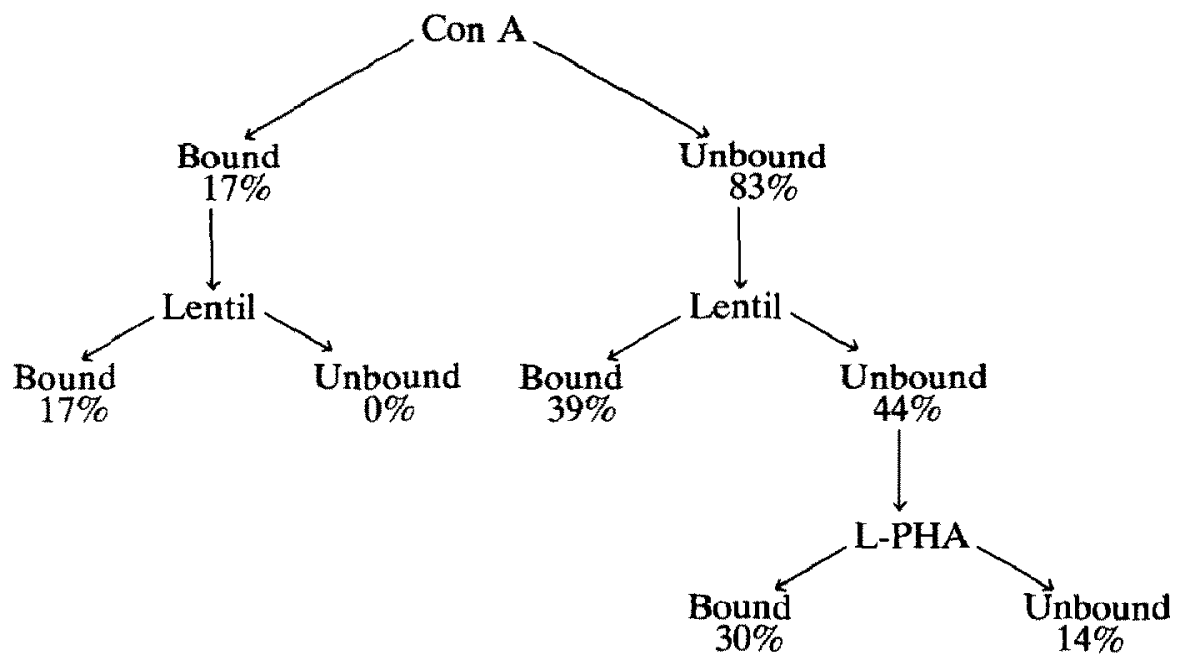

Scheme 1. Characterization of the glycopeptides from the purified glycoprotein, $M_{\mathrm{r}} 200000$, by serial lectin affinity chromatography. The numbers represent the percentage of the total $\left[{ }^{3} \mathrm{H}\right] \mathrm{fucose}$-containing glycopeptides distributed in the bound or unbound fractions from the columns of the specified immobilized lectins. $\left[{ }^{3} \mathrm{H}\right]$ Glycopeptides were obtaincd from the purified glycoprotein (Fig. 3A) after Pronase digestion. Purification of the glycopeptides and all other procedures are referenced in the Experimental section.

$100 \%$ of the Con A bound glycopeptides also bound to lentil lectin-Sepharose, thus demonstrating that a minimum of $56 \%$ of the fucose-labeled glycopeptides contained an $\alpha$-L-Fuc $p$ group $(1 \rightarrow 6)$-linked to the core GlcNAc residue.

At least $69 \%$ of the glycopeptides were larger than diantennary (Scheme 1). Approximately one half of these were of the tetraantennary type, since they bound to immobilized L-PHA ${ }^{16}$ after passage through lentil lectin-Sepharose. The fact that the Con A-unbound glycopeptides were larger than those which were Con A bound was shown also by chromatography on Bio-Gel P-10 in $0.05 \mathrm{M}$ ammonium acetate. The bulk of the Con A-unbound glycopeptides were eluted approximately five fractions before those of the Con A-bound glycopeptides.

The glycoprotein (95\%) bound to serotonin-Sepharose, which suggested that the oligosaccharide residues contained a high percentage of NeuNAc units. Therefore, the binding properties to serotonin-Sepharose of the Con A-bound and -unbound glycopeptides were examined in more detail. The majority ( 92 and $95 \%$ ) of the glycopeptides bound to immobilized serotonin, whether or not they bound to Con A-Sepharose (Table III). After treatment with neuraminidase to remove NeuNAc, 20 and $35 \%$ of the Con A-bound and -unbound glycopeptides, respectively, remained bound to serotonin-Sepharose. The inability to completely abolish the binding after neuraminidase treatment may reflect NeuNAc units having a linkage less susceptible to $V$. cholerae neuraminidase. Alternately, other charged oligosaccharides may bind to serotonin-Sepharose. 
TABLE III

Affinity to serotonin-Sepharose of the glycopeptides from glycoprotein, $M_{\mathrm{r}} 200000$

\begin{tabular}{lllc}
\hline Glycopeptide fraction $^{a}$ & $\begin{array}{l}\text { Neuraminidase added } \\
\text { (Int. units) }\end{array}$ & \multicolumn{2}{l}{ Serotonin-Sepharose (Per cent of total) } \\
\cline { 3 - 4 } Con A-bound & none & Bound & Unbound \\
& 0.01 & 92 & 8 \\
Con A-unbound & none & 20 & 80 \\
& 0.01 & 95 & 5 \\
& & 35 & 65
\end{tabular}

" Glycoprotein, $M_{\mathrm{r}} 200000$, was purified from N-18 cells metabolically labeled with L- $\left[{ }^{3} \mathrm{H}\right]$ fucose; all details are described in the Experimental section.

The charge characteristics of the glycopeptides were examined by separation on DEAE-cellulose. The fucose-labeled glycopeptides were separated into five major classes on the basis of charge (Fig. 4A). Only 5\% of the glycopeptides were neutral, and $30 \%$ were eluted in monoanionic positions ${ }^{15}$. The remaining glycopep-

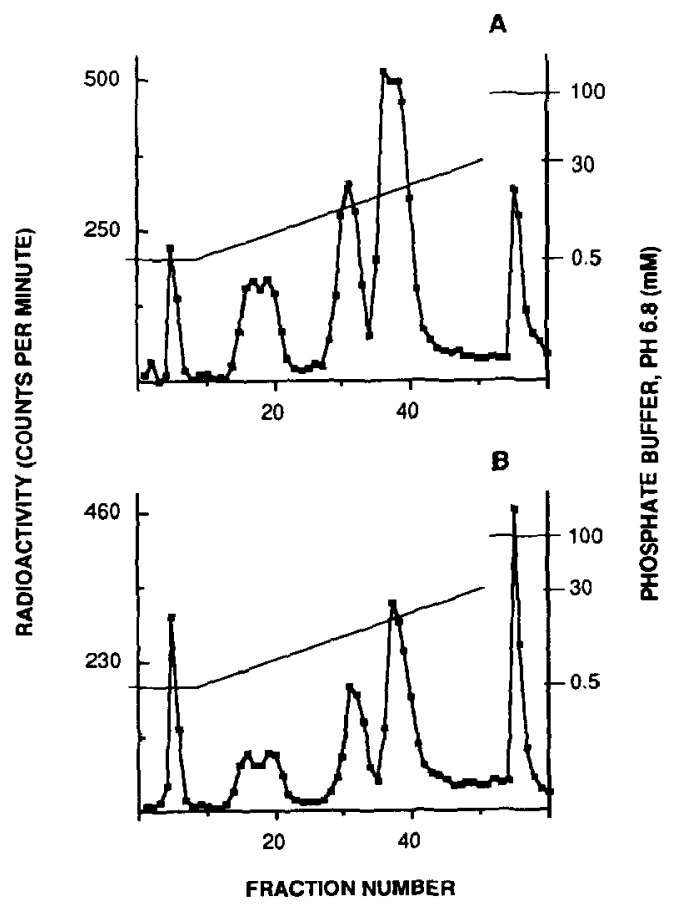

Fig. 4. Charge characteristics of $\left[{ }^{3} \mathrm{H}\right] \mathrm{glycopeptides}$ from the purified glycoprotein, $M_{\mathrm{r}} 200000$. The isolation of the channel was from $\mathrm{N}-18$ cells labeled metabolically with: (A) $\mathrm{L}-\left[{ }^{3} \mathrm{H}\right]$ fucose or (B) $\mathrm{D}-\left[{ }^{3} \mathrm{H}\right] \mathrm{glucosamine} .\left[{ }^{3} \mathrm{H}\right] \mathrm{glycopeptides}$ were derived by Pronase digestion of the purified glycoprotein (see Fig. 3A). The glycopeptides were chromatographed on DEAE-cellulose by use of a gradient of $0.5-30 \mathrm{mM}$ and $0.1 \mathrm{M}$ sodium phosphate buffer, $\mathrm{pH}$ 6.8. All details are described in the Experimental section. 
TABLE IV

$500-\mathrm{MHz}{ }^{1} \mathrm{H}$ NMR chemical shifts of the $\mathrm{N}$-acetyl methyl protons for the Con A-bound fraction and those of reference compound

\begin{tabular}{lll}
\hline $\begin{array}{l}\text { Residue } \\
\text { or group }\end{array}$ & $\begin{array}{l}\text { Chemical shifts } \\
\text { of Con A-bound fraction }\end{array}$ & $\begin{array}{l}\text { Reference } \\
\text { compound }\end{array}$ \\
\hline GlcNAc $^{l}$ & 2.020 & 2.012 \\
GlcNAc $^{2}$ & 2.095 & 2.094 \\
GlcNAc $^{5}$ & 2.048 & 2.048 \\
GlcNAc $^{5}$ & 2.068 & 2.066 \\
NeuNAc $^{7}$ & 2.031 & $2.032^{c}$ \\
NeuNAc $^{7}$ & 2.031 & $2.030^{e}$ \\
\hline
\end{tabular}

${ }^{a}$ For numbering of monosaccharide residues and complete structure, see structure $1{ }^{b}$ Chemical shifts are given downfield from the signal for internal 4,4-dimethyl-4-silapentane-1-sulfonate in $\mathrm{D}_{2} \mathrm{O}\left(27^{\circ}\right)$. ${ }^{c}$ Derived from the purified glycoprotein, $M_{\mathrm{r}} 200000{ }^{d}$ Reference compound from horse-pancreatic ribonuclease (structure 45, ref. 21). ${ }^{e}$ Assignments may have to be interchanged.

tides were more highly charged, and $11 \%$ were eluted only with $100 \mathrm{mM}$ phosphate buffer.

$\mathrm{N}-18$ cells were metabolically labeled with $\mathrm{D}-\left[{ }^{3} \mathrm{H}\right] \mathrm{GlcN}$ and glycoprotein, $M_{\mathrm{r}}$ 200000 , purified as described for the fucose-labeled glycoprotein. The glycopeptides obtained from the $\left[{ }^{3} \mathrm{H}\right] \mathrm{GlcN}$-labeled glycoprotein showed a charge distribution similar to the $\left[{ }^{3} \mathrm{H}\right]$ Fuc-labeled glycopeptides (Figs. $4 \mathrm{~A}$ and $\mathrm{B}$ ). These results verified that all charge classes of glycopeptides were detected with $\mathrm{L}-\left[{ }^{3} \mathrm{H}\right]$ fucose as the metabolic label.

Elucidation of the structures of the Con A-bound glycopeptides. - The glycopeptides that bound to Con A-Sepharose and were eluted with $0.2 \mathrm{mM}$ methyl $\alpha$-D-mannopyranoside were chromatographed on Bio-Gel P-2 to remove methyl $\alpha$-D-mannopyranoside, and then on Bio-Gel P-10, and subsequently two times on Bio-Gel P-2. These glycopeptides representing $18 \%$ of the total fucose-labeled oligosaccharides were subjected to ${ }^{1} \mathrm{H}$ NMR spectroscopy at $500 \mathrm{MHz}$. Owing to the small amount of carbohydrate material, only the chemical shifts of the $\mathrm{N}$-acetyl methyl protons could be clearly discriminated after prolonged scanning. The chemical shifts of these $\mathrm{N}$-acetyl signals are compiled in Table IV, together with those of a reference compound ( $R$ ) from horse-pancreatic ribonuclease (structure 45 , ref. 21).

In the spectrum of the Con A-bound fraction, all $\mathrm{N}$-acetyl signals were of equal intensity, with the exception of the chemical shift at $\delta 2.031$, which had twice the intensity of the other $\mathrm{N}$-acetyl singlets. The absence of any lower-intensity signals between $\delta 2.15$ and 2.00 demonstrated that at least $90 \%$ of the sample consisted of a single component. The signal at $\delta 2.020$ indicated a GlcNAc ${ }^{I}$ linked to an Asn residue $^{21}$. For glycopeptides this chemical shift value varies between $\delta 2.025$ and 2.000 , dependent on the peptide component. The $N$-acetyl protons resonating at $\delta$ 2.095 were attributed to a GlcNAc ${ }^{2}$ residue, linked to an $\alpha$ - $(1 \rightarrow 6)$-fucosylated GlcNAc $^{l}$ residue. In the case of a nonfucosylated GlcNAc $^{l}$ residue, the $N$-acetyl 
group of $\mathrm{GlcNAc}^{2}$ would resonate approximately at $\delta 2.078^{21}$. The chemical shift at $\delta 2.031$ indicated $N$-acetyl protons of a NeuNAc group. The intensity of this signal showed that there were two NeuNAc groups present. In combination with the two remaining $N$-acetyl signals, which were attributed to GlcNAc residues, this pointed to a structure having two branches that were both sialylated. One NeuNAc group was $\alpha$ - $(2 \rightarrow 3)$-linked to a Gal residue as could be deduced from the chemical shift at $\delta$ 2.048. This value is specific for the $N$-acetyl signal of the $\mathrm{GlcNAc}^{5}$ in an $\alpha-(2 \rightarrow 3)$-sialylated branch. The occurrence of a GlcNAc ${ }^{5} .7$, or $7^{\prime}$ residue in an $\alpha$-(2 $\rightarrow 3)$-sialylated branch could be ruled out, because of the absence of $N$-acetyl signals at $\delta 2.044,2.074$, or 2.041 , respectively ${ }^{21,23,24}$. The remaining chemical shift $(\delta 2.068)$ indicated an $\alpha-(2 \rightarrow 6)$-sialylated branch, containing a GlcNAc ${ }^{5}$ or $S^{\prime}$ residue.

The $N$-acetyl protons of a $\mathrm{GlcNAc}^{7}$ residue in this type of branch would resonate at $\delta 2.101^{21.25}$, but no such signal was observed in the spectrum of the Con A-bound fraction. The already mentioned $\alpha$ - $(2 \rightarrow 3)$-sialylation of the GlcNAc ${ }^{5}$ branch leaves a GICNAc ${ }^{5^{\prime}}$ residue as the only candidate present in the $\alpha$-( $2 \rightarrow 6$ )sialylated branch, thus suggesting structure 1 . The $N$-acetyl chemical shifts of the Con A -bound fraction are in good accordance with those described for the reference compound (R) (Table IV). Furthermore, the proposed detailed structure was compatible with information derived by the other methods used to characterize the Con A-bound glycopeptides.

Analysis of the Con A-unbound fraction proved to be heterogeneous (Scheme 1), and additional material will have to be purified to identify the remaining oligosaccharides.

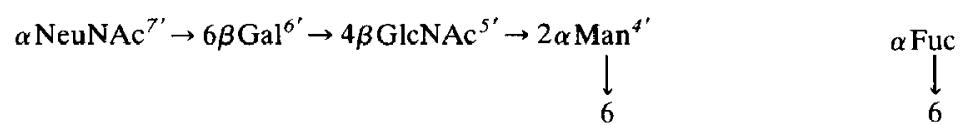

$\alpha \mathrm{NeuNAc}^{7} \rightarrow 3 \beta \mathrm{Gal}^{6} \rightarrow 4 \beta \mathrm{GlcNAc}^{5} \rightarrow 2 \alpha \mathrm{Man}^{4} \rightarrow 3 \beta \mathrm{Man}^{3} \rightarrow 4 \beta \mathrm{GlcNAc}^{2} \rightarrow 4 \beta \mathrm{GlcNAc}^{l} \rightarrow$ NAsn $\alpha$ NeuNAc $=\alpha$-D-NeuNAc- $(2 \rightarrow$

$\beta \mathrm{Gal}=\beta-\mathrm{D}-\mathrm{Gal} p-(1 \rightarrow$

$\beta \mathrm{GlcNAc}=\beta$-D-Glc $p$ NAc- $(1 \rightarrow$

$\alpha \operatorname{Man}=\alpha$-D-Man $p-(1 \rightarrow$

$\beta$ Man $=\beta$-D-Man $p-(1 \rightarrow$

$\alpha$ Fuc $=\alpha$-L-Fuc $p-(\rightarrow$

\section{DISCUSSION}

A glycoprotein, $M, 200000$, isolated from mouse neuroblastoma cells, had the biological activity of the neurotoxin-responsive $\mathrm{Na}^{+}$channel. This activity was shown to depend on the presence of NeuNAc groups (Table II) and was demonstrated by the dramatic loss of the ability of the neurotoxins to activate ${ }^{86} \mathrm{Rb}$ flux 
when NeuNAc groups were removed from the channel glycoprotein. For these experiments, the purified glycoprotein (Fig. 3A) was treated with neuraminidase after reconstitution into artificial phospholipid vesicles. Under such conditions, the channel is already inserted into the lipid bilayer and the protein backbone cannot be metabolically altered, criticism afforded previous experiments ${ }^{2,4}$ which used inhibitors of glycoprotein synthesis.

The glycoprotein, which had the properties of the neurotoxin-responsive $\mathrm{Na}^{+}$ channel, was purified to apparent electrophoretic homogeneity by mild methods used in glycoprotein separation (Fig. 3A), thus yielding material readily amenable to retaining the biological activity of ion flux after reconstitution into phospholipid vesicles (Table I). There is a discrepancy between the apparent molecular mass of the purified glycoprotein and preparations reported by others to possess toxinbinding activity ${ }^{12,26}$. It is possible that mouse neuroblastoma, clone $\mathrm{N}-18$, has channel subunits that are normally of smaller size. It cannot be ruled out that during our harvesting procedure, specific proteases act on the glycoprotein. If another portion of the polypeptide backbonc exists, it does not appear to contribute to the biological function of the channel from these mouse cells. More heterogeneous subunits have been reported for saxitoxin binding and $\mathrm{Na}^{+}$flux in material purified from rat brain ${ }^{27}$. The smaller subunits were not accounted for in molecular cloning ${ }^{28}$, thus suggesting artifactual results if purification is only followed by toxin binding.

The characterization of the oligosaccharide residues by lectin-binding properties showed that a large portion $(69 \%)$ of the fucose-containing oligosaccharides present on this large polypeptide may contain tri- and tetra-antennae (Scheme 1), more than $90 \%$ of which are sialylated (Table III). Glycoproteins of tumor cells are known to contain oligosaccharides with more sialylated, complex branching that those of nontumor cells ${ }^{18}$. Therefore, it will be interesting to know whether or not the $\mathrm{Na}^{+}$channels from nontumor cells express a similar complement of oligosaccharides. High resolution ${ }^{1} \mathrm{H}$ NMR spectroscopy showed unequivocally the diantennary structure of $\sim 20 \%$ of the oligosaccharides (Table IV), that is, those which bound to Con A. A $(2 \rightarrow 3)$-linked $\alpha$-NeuNAc group was present on the $\mathrm{GlcNAc}^{5}$ antenna, whereas a $(2 \rightarrow 6)$-linked $\alpha$-NeuNAc group was present on the GIcNAc $^{5}$ antenna. The GlcNAc ${ }^{l}$ residue was substituted with a $(1 \rightarrow 6)$-linked $\alpha$-L-Fuc group.

Noda et al. ${ }^{29}$ reported that the cloned electroplax $\mathrm{Na}^{+}$channel of Electrophorus electricus contained 10 potential sites for glycosylation. The glycosylated sites of the mouse neuroblastoma $\mathrm{Na}^{+}$channel had fucosylated oligosaccharides of the di-, tri-, and tetra-antennary typc in the ratio 2:4:3 (Scheme 1). Assuming 9-10 potential sites for glycosylation and that most of these oligosaccharides are fully sialylated (Table III), the oligosaccharide content will be a total of $\sim 32000$ daltons and will account for $15 \%$ glycosylation by weight. On the other hand, it has been reported ${ }^{30}$ that the carbohydrate content of the electroplax $\mathrm{Na}^{+}$channel was $\sim 30 \%$ by weight and that polysialic acid contributed to this weight ${ }^{31}$. 
Polymers of sialic acid in purified preparations of the $\mathrm{Na}^{+}$channel from $\mathrm{N}-18$ cells were not detected with endoneuraminidase ${ }^{32,33}$, although polymers containing $>55$ sialyl residues were readily demonstrated among the glycoproteins of human neuroblastoma cells ${ }^{34}$. In this regard, N-CAM immunoprecipitated from mouse neuroblastoma, $\mathrm{N}-18$, was of the adult form ${ }^{35}$, whereas that from human neuroblastoma was of the embryonic form ${ }^{34}$. Adult N-CAM is distinquished from embryonic N-CAM by containing shorter polymers of sialic acid ${ }^{36}$. Therefore, it is possible that the $\mathrm{Na}^{+}$channel of $\mathrm{N}-18$ cells will contain only short oligomers of sialic acid in contrast to that of the electric eel ${ }^{31}$. If further experimentation provides proof of short oligomers, it will explain the smaller size of the $\mathrm{Na}^{+}$ channel in $\mathrm{N}-18$ cells.

It was hypothesized originally by Lehninger ${ }^{37}$ that sialic acid was necessary for ion flux, however the possibility has not been extensively explored. The findings reported herein support this hypothesis. Support is also derived from the observation that the genes which control the complete biological expression of the $\mathrm{Na}^{+}$ channel have been found on more than one chromosome; tetrodotoxin inhibition and veratridine stimulation were shown to separate discordantly in cell hybrids ${ }^{38}$. It may be possible that poly- and mono-sialyltransferases will exert a controling role in the biological activity of the mature $\mathrm{Na}^{+}$channel, perhaps by way of conformational changes in the resulting oligosaccharides ${ }^{39}$.

\section{ACKNOWLEDGMENTS}

The technical assistance of Ms. Florence Massey and Jean Kershaw is gratefully acknowledged. This investigation was supported by U.S. Public Health Service grants HD-08356 and CA-37853 (to M.C.G.); The Netherlands Foundation for Chemical Research, S.O.N.; The Netherlands Organization for Scientific Research, N.W.O. (to J.F.G.V.); and NATO Collaborative Research Grant 0512/87.

\section{REFERENCES}

1 M.Y. Giovanni and M.C. Glick, Proc. Natl. Acad. Sci. U.S.A., 80 (1983) 4537-4541.

2 M. Negishi and M.C. Glick, Carbohydr. Res., 149 (1986) 185-198.

3 M.Y. Giovanni, D. Kessel, and M.C. Glick, Proc. Natl. Acad. Sci. U.S.A., 78 (1981) 1250-1254.

4 C.J. Waechter, J.W. Schmidt, and W.A. Catterall, J. Biol. Chem., 258 (1983) 5117-5123.

5 W.A. Catterall, Annu. Ret: Biochem., 55 (1986) 953-958.

6 B. Hille, Biophys. J., 22 (1978) 283-294.

7 D.W. Tank, R.L. Huganir, P. Greengard, and W.W. Webb, Proc. Natl. Acad. Sci. U.S.A., 80 (1983) $5129-5133$.

8 X-C. Yang, A. Karschin, C. Labarca, O. Elroy-Stein, B. Moss, N. Davidson, and H.A. Lester, FASEB J., 5 (1991) 2209-2216.

9 C. Palfrey and U.Z. Littauer, Biochem. Biophys. Res. Commun., 72 (1976) 209-215.

10 B.K. Schrier, S.H. Wilson, and M. Nirenberg, Meth. Enzymol., 32 (1974) 765-788.

11 U.Z. Littauer, M.Y. Giovanni, and M.C. Glick, J. Biol. Chem., 255 (1980) 5448-5453.

12 R.J. Barchi, Annu. Rev. Neurosci., 11 (1988) 455-495.

13 U.H. Lowry, N.J. Rosenbrough, A.L. Farr, and R.J. Randall, J. Biol. Chem., 193 (1951) 265-275. 
14 M. Epstein and E. Racker, J. Biol. Chem., 253 (1978) 6660-6662.

15 M.C. Glick, Biochemistry, 18 (1979) 2525-2532.

16 R.D. Cummings and S. Kornfeld, J. Biol Chem., 257 (1982) 11235-11240.

17 H. Debray, A. Pierce-Cretel, G. Spik, and J. Montreuil, Lectins, 3, Walter de Gruyter, Berlin, 1983, pp. 335-350.

18 U.V. Santer, R. DeSantis, K.J. Hård, J.A. van Kuik, J.F.G. Vliegenthart, B. Won, and M.C. Glick, Eur. J. Biochem., 181 (1989) 249-260.

19 R.J. Sturgeon and C.M. Sturgcon, Carbohydr. Res., 103 (1982) 213-219.

20 C.P. Stowell, T.F. Scanlin, and M.C. Glick, Carbohydr. Res., 151 (1986) 279-292.

21 J.F.G. Vliegenthart, L. Dorland, and H. van Halbeek, Adt. Carbohydr. Chem. Biochem., 41 (1983) $209-374$.

22 R.R. Ernst, Adv. Magn. Res., 2 (1966) 1-135.

23 G. Spik, V. Debruyne, J. Montreuil, H. van Halbeek, and J.F.G. Vliegenthart, FEBS Lett., 183 (1985) 65-69.

24 J.B.L. Damm, A.A. Bergwerf, K. Hård, J.P. Kamerling, and J.F.G. Vliegenthart, Recl. Trat: Chim. Pays-Bas, 108 (1989) 351-359.

25 D.H. Joziasse, W.E.C.M. Schiphorst, D. van den Eijnden, J.A. van Kuik, H. van Halbeek, and J.F.G. Vliegenthart, J. Biol. Chem., 262 (1987) 2025-2033.

26 W.S. Agnew, Annu. Rev. Physiol., 46 (1984) 517-530.

27 D.J. Feller, J.A. Talvenheimo, and W.A. Catterall, J. Biol. Chem., 260 (1985) 11542-11547.

28 M. Noda and S. Numa, J. Recept. Res., 7 (1987) 467-497.

29 M. Noda, S. Shimizu, T. Tanabe, T. Takai, T. Kayano, T. Ikeda, H. Takahashi, H. Nakayama, Y. Kanaoka, N. Minamino, K. Kangawa, H. Matsuo, M.A. Raftery, T. Hirose, S. Inayama, H. Hayashida, T. Miyata, and S. Numa, Nature (London), 312 (1984) 121-127.

30 J.A. Miller, W.S. Agnew, and S.R. Levinson, Biochemistry, 22 (1983) 462-470.

31 W.M. James, M.C. Emerick, and W.S. Agnew, Biochemistry, 28 (1989) 6001-6009.

32 R.D. McCoy, E.R. Vimr, and F.A. Troy, J. Biol. Chem., 260 (1985) 1269512699.

33 J. Jacobs, G. Shaw, F.A. Troy, and M.C. Glick, unpublished results.

34 B.D. Livingston, J.L. Jacobs, M.C. Glick, and F.A. Troy, J. Biol. Chem., 263 (1988) 9443-9448.

35 M. Negishi and M.C. Glick, unpublished results.

36 G.M. Edelman, Annu. Rev. Biochem., 54 (1985) 135-169.

37 A.L. Lehninger, Proc. Natl. Acad. Sci. U.S.A., 60 (1968) 1069-1080.

38 F. Gilbert, M.Y. Giovanni, I.A. Silver, and M.C. Glick, FEBS Lett., 236 (1988) 39-42.

39 J. Montreuil, Biol. Cell, 51 (1984) 115-131. 